\title{
Management of Abdominal Trauma with Liver Injuries among Patients in Riyadh, Saudi Arabia
}

\author{
Khaled Abdullah Alshareef ${ }^{1 *}$, Amirah Mohammed Alosaimi ${ }^{1}$, Luay Mohammed \\ Sahyun $^{2}$, Hashem Mohammed Justaniah ${ }^{2}$, Mahmoud Talat Khodary ${ }^{2}$, Faisal Khalid \\ Alhothali $^{3}$, Yasir Mohammed Alsagoor ${ }^{4}$, Yaser Abbas Alnajrani ${ }^{5}$ \\ ${ }^{1}$ Almaarefa Colleges, Riyadh, ${ }^{2}$ IbnSina National College for Medical Studies, Jeddah, \\ ${ }^{3}$ University of Jeddah, Saudi Arabia, ${ }^{4}$ University of Groningen, Netherlands, ${ }^{5}$ University of \\ Najran, Saudi Arabia \\ *Corresponding Author: Khaled Abdullah Alshareef, E-mail: Khaled.alshareef@hotmail.com
}

\begin{abstract}
Background: recently, there was a shift in the management plan for liver blunt trauma from operative to non-operative treatment, as there were advances in critical care and sensitivity of diagnostic tools for detection of liver injury such as CT scan. Objectives: To estimate the prevalence and correlates of non-operative management of liver injury among abdominal trauma patients admitted under surgical team care. Patients and Methods: this is a retrospective cohort study carried out in Riyadh, Saudi Arabia from May 2017 to June 2018. All patients admitted to general surgery departments with abdominal trauma and liver injuries were included. Variables were obtained through file review. Results: the study included 54 patients with liver trauma. Their age ranged from 7 to 60 years with mean age of 29.2 \pm 11.3 . Male was the dominant gender; with male to female ratio were 8 to 1 . Regarding mechanism of injury, all cases of fall down and $88.9 \%$ of road traffic accidents compared to none of penetrating injury were treated non-operatively, $\mathrm{p}=0.011$. Concerning $\mathrm{CT}$ grading, all cases of grade I compared to $75 \%$ of grade IV and $70 \%$ of grade III were treated non-operatively, $\mathrm{p}=0.016$. Majority of patients treated non-operatively $(45 / 48 ; 93.8 \%)$ compared to one third of those treated operatively $(2 / 6 ; 33.3 \%)$ were improved on discharge, $\mathrm{p}<0.001$. Conclusion: the prevalence of non-operative management of liver injury in Riyadh hospitals is currently very high, ever for high-grade injuries. Most of them were improved on discharge compared to those managed operatively.
\end{abstract}

Keywords: Liver Injury, Non-Operative, Operative, Retrospective Cohort.

\section{INTRODUCTION}

Operative management of liver trauma was considered the golden standard of treatment before two decades ${ }^{(1)}$. Recently, there was a shift in the management plan from operative to non-operative treatment, as there were advances in critical care and sensitivity of diagnostic tools for detection of liver injury such as CT scan ${ }^{(2)}$. Nonoperative management started by conserving low-grade liver injury and it's proved to be a good tool, higher grades of liver injuries also treated non-operatively and it decreased the morbidity complication rate of operative treatment ${ }^{(3)}$. Patients with hepatic trauma associated with hemodynamic instability and comorbid organ injuries need surgery as they are subjected to higher mortality ${ }^{(4,5)}$.
Therefore, surgeons should understand the indications for operative intervention well (6). Non-operative management of liver trauma should be carried out if possible in every patient provided he is hemodynamicaly stable. Riyadh hospitals in receive huge number of MVA (motor vehicle accident), and Saudi Arabia considered having one of the highest rates of RTA in the world ${ }^{(7)}$.

Abdominal trauma and liver injury is one of the commonest presentations in Riyadh hospitals. This study carried out because of limited studies addressing this issue in the kingdom of Saudi Arabia to estimate the prevalence and correlates of non-operative management of liver injury among abdominal trauma patients admitted under 
surgical team care in Riyadh hospitals fromMay 2017 to June 2018.

\section{PATIENTS AND METHODS}

This is a retrospective cohort study carried out in Riyadh hospitals from May 2017 to June 2018. All patients admitted to hospitals in general surgery department with abdominal trauma and liver injury was included. Variables such as Glasgow coma scale, CT grading system, number of PRBC units transfused, hemodynamic stability and associated injuries were considered in this study. These variables were obtained through file review. Fiftyfour were recruited for this study. On presentation to ER all the patients were assessed and resuscitated if necessary, in accordance with ATLS protocol. Demographic details and history including the mechanism of injury were recorded. All the patients underwent FAST and once stable, they were further evaluated with CECT abdomen and pelvis for details of solid organ injury and its grade. Patients who satisfied the inclusion criteria were included in the study. For all patients' blood pressure, heart rate, Glasgow Coma Scale (GCS) score, haemoglobin ( $\mathrm{Hb}$, packed cell volume (PCV), abdomen girth chart, associated injuries and its influence on the patients outcome and hospital stay, length of hospital stay (LOS), total blood products (TBP) transfused, time of conversion (TOC) and the reasons for conversion, complications in the converted group, outcome of each patients and mortality if any were recorded. American association for the surgery of trauma grading system (19) was used to define grades of liver injury.

\section{Statistical Analysis}

Data were analysed using SPSS for Windows version 22.0 (SPSS Inc., Chicago, IL, USA). Statistical comparisons of means and medians were made using the Mann-Whitney $U$-test. Comparisons of proportions were made using $\chi^{2}$ analysis with Pearson's correlation coefficient or Fisher's exact test when appropriate. Grading correlations was performed using Spearman's rank correlation test. Data are expressed as mean \pm SD unless otherwise stated. A value of $P<0.05$ was considered significant.

\section{RESULTS}

The study included 54 patients with liver trauma. Their age ranged from 7 to 60 years with mean age of $29.2 \pm 11.3$. Male was the dominant gender; with male to female ratio were 8 to 1 . Exactly half of patients were Saudis.

Figure 1 shows that the prevalence of nonoperative management of liver injury throughout the period fromMay 2017 to June 2018 was $88.9 \%$.

Table 1 summarizes the difference between operative and non-operative patients regarding different characteristics. There was no significant difference between both groups regarding age, gender and nationality of patients. Regarding mechanism of injury, all cases of fall down and $88.9 \%$ of road traffic accidents compared to none of penetrating injury were treated non-operatively, $\mathrm{p}=0.011$. Concerning CT grading, all cases of grade I compared to $75 \%$ of grade IV and $70 \%$ of grade III were treated non- operatively, $\mathrm{p}=0.016$. Systolic and diastolic pressures were significantly higher in patients managed non-operatively than those managed operatively $(123.5 \pm 18.8$ and $75.4 \pm 13.9$ versus $92.3 \pm 41.4$ and $56.0 \pm 25.9$ ); $p$ values were 0.002 and 0.005 for systolic and diastolic blood pressures, respectively. Heart rate was higher in patients treated operatively than those treated non-operatively $(114.2 \pm 16.9$ versus 98.7 \pm 20.7$)$. However, the difference was not statistically significant. There was no significant difference between both groups regarding hematological parameters except PTT as it was $48.8 \pm 30.0$ in operative group and $31.7 \pm 10.0$ in non-operative group, $\mathrm{p}=0.009$. Majority of patients with 14-15 Glasgow coma scale (97.3\%) compared to $71.4 \%$ of those of $\leq 8$ 
Glasgow coma scale were treated nonoperatively, $\mathrm{p}=0.014$.

All cases presented without associated abdominal injury compared to $70 \%$ of those presented with associated abdominal injury were managed non-operatively, $p=0.002$. There were no statistically significant difference between both groups regarding co-morbidity, FAST results, total days of admission and total days under general surgery.

Majority of patients treated nonoperatively $(45 / 48 ; 93.8 \%)$ compared to one third of those treated operatively $(2 / 6$; $33.3 \%$ ) were improved on discharge, $\mathrm{p}<0.001$.

Table 1: Factors associated with management of liver injury among abdominal trauma patients

\begin{tabular}{|c|c|c|c|c|}
\hline & & $\begin{array}{l}\text { Non-operative } \\
\mathrm{N}=48\end{array}$ & $\begin{array}{l}\text { Operative } \\
\mathrm{N}=6\end{array}$ & p-value \\
\hline Age (years) [mean \pm SD] & & $29.7 \pm 12.1$ & $25.0 \pm 7.7$ & $0.357 *$ \\
\hline \multirow[t]{2}{*}{ Gender } & Male $(n=46)$ N (\%) & $41(89.1)$ & $5(10.9)$ & \multirow[t]{2}{*}{$0.637 * *$} \\
\hline & Female $(n=8)$ N (\%) & $7(87.5)$ & $1(12.5)$ & \\
\hline \multirow[t]{2}{*}{ Nationality } & Saudi (n=27) N (\%) & $23(85.2)$ & $4(14.8)$ & \multirow[t]{2}{*}{$0.334 * *$} \\
\hline & Non-Saudi (n=27) N (\%) & $25(92.6)$ & $2(7.4)$ & \\
\hline \multirow[t]{3}{*}{ Mechanism of injury } & RTA $(n=45)$ N (\%) & $40(88.9)$ & $5(11.1)$ & \multirow[t]{3}{*}{$0.011^{\circ}$} \\
\hline & Fall down $(\mathrm{n}=8) \mathrm{N}(\%)$ & $8(100)$ & $0(0.0)$ & \\
\hline & Penetrating $(n=1)$ N $(\%)$ & $0(0.0)$ & $1(100)$ & \\
\hline \multirow[t]{4}{*}{ CT grading of liver injury } & GI $(n=19) \mathbf{N}(\%)$ & $19(100)$ & $0(0.0)$ & \multirow[t]{4}{*}{$0.016^{\circ}$} \\
\hline & GII $(n=21)$ N (\%) & $19(90.5)$ & $2(9.5)$ & \\
\hline & GIII $(n=10)$ N (\%) & $7(70.0)$ & $3(30.0)$ & \\
\hline & GIV $(n=4)$ N(\%) & $3(75.0)$ & $1(25.0)$ & \\
\hline \multirow[t]{2}{*}{ Haemodynamic status } & Stable $(n=39)$ & $36(92.3)$ & $3(7.7)$ & \multirow[t]{2}{*}{$0.205 * *$} \\
\hline & Unstable $(n=15)$ & $12(80.0)$ & $3(20.0)$ & \\
\hline Systolic blood pressure [mean \pm SD] & & $123.5 \pm 18.8$ & $92.3 \pm 41.4$ & $0.002 *$ \\
\hline Diastolic blood pressure $[$ mean $\pm \mathrm{SD}]$ & & $75.4 \pm 13.9$ & $56.0 \pm 25.9$ & $0.005^{*}$ \\
\hline Heart rate $[$ mean \pm SD] & & $98.7 \pm 20.7$ & $114.2 \pm 16.9$ & $0.106^{*}$ \\
\hline Haemoglobin [mean \pm SD] & & $12.6 \pm 2.1$ & $10.9 \pm 3.5$ & $0.098^{*}$ \\
\hline Plateletes[mean \pm SD] & & $254.2 \pm 87.9$ & $204.0 \pm 69.7$ & $0.224 *$ \\
\hline Haematocrite[mean \pm SD] & & $36.9 \pm 5.4$ & $31.8 \pm 9.4$ & $0.072 *$ \\
\hline ALT $[$ mean \pm SD $]$ & & $305.2 \pm 254.7$ & $371.8 \pm 332.4$ & $0.594^{*}$ \\
\hline AST $[$ mean \pm SD] & & $323.1 \pm 285.4$ & $448.4 \pm 383.2$ & $0.377 *$ \\
\hline PTT $[$ mean \pm SD] & & $31.7 \pm 10.0$ & $48.8 \pm 30.0$ & $0.009 *$ \\
\hline \multirow[t]{3}{*}{ Glasgow coma scale } & 14-15 (n=37) N (\%) & $36(97.3)$ & $1(2.7)$ & \multirow[t]{3}{*}{$0.014^{\circ}$} \\
\hline & $9-13(n=3) N(\%)$ & $2(66.7)$ & $1(33.3)$ & \\
\hline & $\leq 8(n=14) N(\%)$ & $10(71.4)$ & $4(28.6)$ & \\
\hline \multirow[t]{2}{*}{ Associated abdominal injury } & Yes $(n=20)$ N (\%) & $14(70.0)$ & $6(30.0)$ & \multirow[t]{2}{*}{$0.002^{\circ}$} \\
\hline & No $(n=34) \mathbf{N}(\%)$ & $34(100)$ & $0(0.0)$ & \\
\hline \multirow[t]{2}{*}{ Co-morbidity } & Yes $(n=3) \mathbf{N}(\%)$ & $3(100)$ & $0(0.0)$ & \multirow[t]{2}{*}{$0.697^{\circ}$} \\
\hline & No $(n=51) N(\%)$ & $45(88.2)$ & $6(11.8)$ & \\
\hline \multirow[t]{3}{*}{ FAST results } & Free fluid $(n=12) \mathbf{N}(\%)$ & $9(75.0)$ & $3(25.0)$ & \multirow[t]{3}{*}{$0.185^{\circ}$} \\
\hline & No free fluid $(n=6)$ N (\%) & $6(100)$ & $0(0.0)$ & \\
\hline & Not done $(n=36) \mathbf{N}(\%)$ & $33(91.7)$ & $3(8.3)$ & \\
\hline Total days of admission [mean $\pm \mathrm{SD}]$ & & $12.13 \pm 11.4$ & $12.0 \pm 20.1$ & $0.982 *$ \\
\hline $\begin{array}{l}\text { Total days under general surgery (GS) } \\
{[\text { mean } \pm \mathrm{SD}]}\end{array}$ & & $5.9 \pm 4.4$ & $3.2 \pm 3.5$ & $0.153^{*}$ \\
\hline \multirow[t]{3}{*}{ Condition on discharge } & Improved (n=47) N (\%) & $45(95.7)$ & $2(4.3)$ & \multirow[t]{3}{*}{$<0.001^{\circ}$} \\
\hline & Expired under GS $(n=6)$ N (\%) & $2(33.3)$ & $4(66.7)$ & \\
\hline & Expired under others $(n=1)$ N (\%) & $1(100)$ & $0(0.0)$ & \\
\hline
\end{tabular}

*Student`s t-test; **Fischer exact test; ${ }^{\circ}$ Chi-square test 


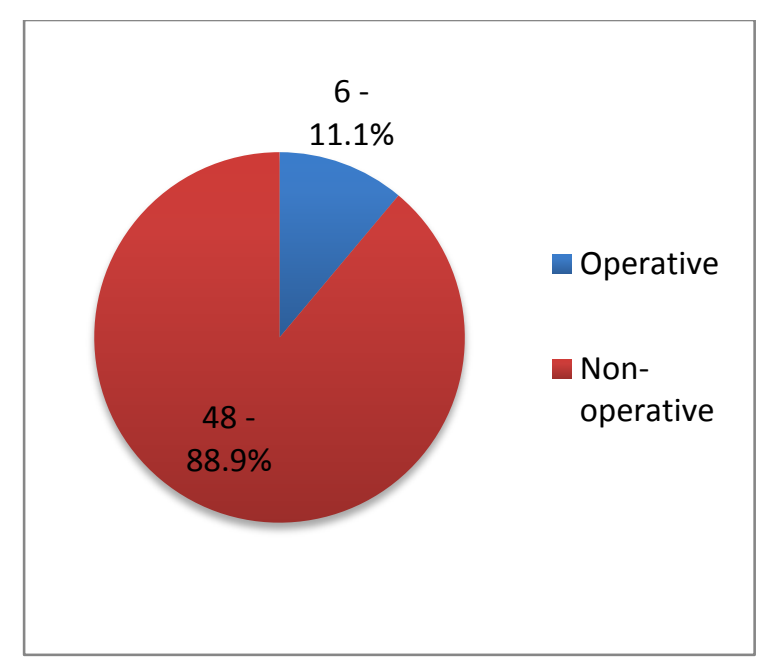

Figure 1: Prevalence of non-operative management of liver injury.

\section{DISCUSSION}

Concerning the mechanism of liver injury, the most frequent cause in the present study was traffic accidents $(83.3 \%$ " $45 / 54$ "). This is higher to what has been reported by others in Korea $(49.7 \%)^{(8)}$, Scotland $\quad(54 \%)^{(9)}$,USA $(72 \%)^{(10)}$, and United Kingdom "UK" (67\%) ${ }^{(11)}$.

Male predominance is apparent in the present study $(85.2 \%)$. The same has been proved in several worldwide studies including Korea $(69 \%)^{(8)}$,Scotland $(76 \%)^{(9)}, \mathrm{UK} \quad(79 \%)^{(11)}$,United States $(65 \%)^{(10)}$,and South Africa $(81 \%)^{(12)}$.

As regards the grade of liver injury, $92.6 \%$ (50/54) of traumatic liver injuries in the present study were low-grade (I, II, or III). In Korea, $70.9 \%$ of traumatic liver injuries were low grade ${ }^{(8)}$. In USA, a rate of lowgrade liver injuries was $80 \%^{(10)}$.In Scotland, $69 \%$ of traumatic liver injuries were grade II $^{(9)}$.

As expected the magnitude of nonoperative management of traumatic liver injury was higher considerably compared to operative management. This is most probably due the new advancement in diagnostic tools and intensive care management ${ }^{(13)}$. This result is similar to other published studies ${ }^{(8,14,15)}$. As expected grade II liver injury was successfully treated non-operatively (90.5\%). However, (75\%) of grade IV liver injury was treated non-operatively which is an outstanding result and unexpectedly high. This finding might be explained by presence of good training program for general surgery residents, availability of blood bank and quick response of emergency department personnel at Riyadh hospitals.

Usually surgeons determine the treatment strategy for traumatic liver injury according to a patient's hemodynamic status rather than the grade of liver injury. Van der Wilden et al. ${ }^{(16)}$ observed that liver injury grade was not significantly associated with non-operative treatment success. Also, Zago et al. ${ }^{(17)}$ reported no significant difference between operative and non-operative groups regarding grade of liver injury. However, Pachter et al. ${ }^{(10)}$ suggested that most cases of failed nonoperative treatment occurred in patients with severe grades of liver injuries.

\section{CONCLUSION}

The prevalence of non-operative management of liver injury in Riyadh hospitals is currently very high, ever for high-grade injuries. Most of them were improved on discharge compared to those managed operatively.

\section{LIMITATIONS:}

There were some limitations of this study that should be mentioned. This study was retrospective cohort study. We couldn't assess the reasons of non-operative treatment failure as we depend only on record reviewing. However, in the present study, we compared the clinical characteristics between operative and nonoperative groups of treatment of traumatic liver injury. There were significant differences between the two groups for: grade of liver injury, systolic and diastolic pressures, PTT, Glasgow coma scale, and associated abdominal injury.

Considering the results of this study, we suggest that grade of liver injury, PPT, Glasgow coma scale, blood pressure and associated abdominal injury may be 
helpful when determining the treatment of traumatic liver injury: grade of liver injury.

\section{REFERENCES}

1. David Richardson J, Franklin GA, Lukan JK, Carrillo EH, Spain DA et al. (2000): Evolution in the management of hepatic trauma: a 25year perspective. Ann Surg., 232: 324330.

2. Parks RW, Chrysos E, Diamond TM (1999): Management of liver trauma. Br J Surg., 86: 1121-1135.

3. Croce MA, Fabian TC, Menke PG, Waddle-Smith L, Minard G, Kudsk KA et al. (1995): Non-operative management of blunt hepatic trauma is the treatment of choice for hemodynamicaly stable patients, Results of a prospective trial. Ann Surg., 221(6): 744-755.

4. Somasundar PS, Mucha P, McFadden DW (2004): The evolving management of blunt hepatic trauma. Am Surg., 70:45-8.

5. Yoon W, Jeong YY, Kim JK, Seo JJ, Lim HS, Shin SS et al. (2005): CT in blunt liver trauma. Radiographics, 25:87-104.

6. Bismar HA, Alam MK, Al-Keely MH, Alsalamah SM, Mohammed AA (2004): Outcome of non-operative management of blunt liver trauma. Saudi Med J., 25: 294-8.

7. Mansuri FA, Al-Zalabani AH, Zalat MM, Qabshawi RI(2015):Road safety and road traffic accidents in Saudi Arabia: A systematic review of existing evidence. Saudi Med J., 36(4): 418-424.

8. Park KB, You DD, Hong TH, Heo JM, Won YS (2015):Comparison between operative versus nonoperative management of traumatic liver injury. Korean J Hepatobiliary Pancreat Surg., 19(3): 103-108.

9. Scollay JM, Beard D, Smith R, McKeown D, Garden OJ, Parks R (2005): Eleven years of liver trauma: the Scottish experience. World J Surg., 29: 744-749.

10. Pachter HL, Knudson MM, Esrig B, Ross S, Hoyt D, Cogbill T et al. (1996): Status of non-operative management of blunt hepatic injuries in 1995: a multicenter experience with 404 patients. J Trauma, 40:31-38.

11. Brammer RD, Bramhall SR, Mirza DF, Mayer AD, McMaster P, Buckels JA (2002): A 10-year experience of complex liver trauma. $\mathrm{Br}$ J Surg., 89:1532-1537.

12. Krige JE, Bornman PC, Terblanche J (1997):Liver trauma in 446 patients. S Afr J Surg., 35:10-1

13. Cirocchi R, Trastulli S, Pressi E, Farinella E, Avenia S, Morales Uribe CH et al. (2015): Non-operative management versus operative management in high-grade blunt hepatic injury. Cochrane Database Syst Rev., 24(8):CD010989.

14. Saltzherr TP, van der Vlies $C H$, van Lienden KP, Beenen LFM, Ponsen KJ, vanGulik TM et al. (2011):Improved outcomes in the nonoperative management of liver injuries. HPB (Oxford), 13(5): 350-355.

15. Velmahos GC, Toutouzas K,Radin R, Chan L, Demetriades D (2003): Non-operative treatment of blunt injury to solid abdominal organs: a prospective study. Arch Surg., 138: 844-851.

16. Van der Wilden GM, Velmahos GC, Joseph DK, Jacobs L, Debusk MG, Adams CA et al. (2013): Successful non-operative management of the most severe blunt renal injuries: a multicenter study of the research consortium of New England Centers for Trauma. JAMA Surg.,148: 924931.

17. Zago TM, Pereira BM, Calderan TR, Hirano ES, Rizoli S, Fraga GP (2012): Blunt hepatic trauma: comparison between surgical and nonoperative treatment. Rev Col Bras Cir., 39: 307-313. 
18. Gaarder C, Naess PA, Eken T, Skaga NO, Pillgram-Larsen J, Klow $\mathrm{NE}$ et al. (2007): Liver injuries improved results with a formal protocol including angiography. Injury, 38:1075-1083.
19. Moore EE, Cogbill TH, Jurkovich GJ, Shackford SR, Malangoni MA, Champion HR (1995): Organ injury scaling: spleen and liver (1994 revision) J Trauma, 38:323-324. 